\title{
Perception of bronchoconstriction in asthma patients measured during histamine challenge test
}

\author{
I.D. Bijl-Hofland*, H.Th.M. Folgering**, H. van den Hoogen*, S.G.M. Cloosterman*, C. Van Weel*, \\ J.M. Donkers*, C.P. van Schayck*
}

Perception of bronchoconstriction in asthma patients measured during histamine challenge test. I.D. Bijl-Hofland, H.Th.M. Folgering, H. van den Hoogen, S.G.M. Cloosterman, C. Van Weel, J.M. Donkers, C.P. van Schayck. (C)ERS Journals Ltd 1999.

ABSTRACT: This study investigated two aspects of the perception of bronchoconstriction ("sensitivity" and "absolute perceptual magnitude") in asthmatic patients and identified which clinical characteristics are related to these two aspects of perception of bronchoconstriction.

The perception of histamine induced bronchoconstriction was measured in 128 asthmatic patients. Subjects quantified their breathlessness on a Visual Analogue Scale (VAS) before forced expiratory volume in one second (FEV1 was measured after each inhalation of histamine. The perceptive "sensitivity" for changes in FEV1 was analysed by the "VAS percentage fall in FEV1" slope. The "absolute perceptual magnitude" was determined by the VAS value at a $20 \%$ fall in FEV1. Spearman correlations were used for analysis between the two aspects of perception and asthma symptoms, peak flow variablity, bronchial responsiveness and FEV1 \% predicted.

Patients with a low "sensitivity" for changes in FEV1 were more likely to show a frequent peak flow variability $(\mathrm{Rs}=-\mathbf{0 . 2 1} ; \mathbf{p}<0.05)$, a high bronchial responsiveness $(\mathrm{Rs}=$ $0.37 ; p<0.001)$ and a low baseline FEV1 \% pred $(R s=0.22 ; p<0.05)$. Patient's "absolute perceptual magnitude" correlated positively with symptoms during daily life (significant correlations varied $0.21-0.32$ ) but not with the lung function parameters.

The severity of asthma reflected by a low lung function and a high bronchial responsiveness, is associated with a low "sensitivity" for changes in forced expiratory volume in one second. A patient's "absolute perceptual magnitude" is positively related with asthma symptoms during daily life.

Eur Respir J 1999; 14: 1049-1054.
*Dept of General Practice and Socia Medicine, University of Nijmegen, the Netherlands **Dept of Pulmonary Diseases, Dekkerswald, University of Nijmegen, the Netherlands

Correspondence: I.D. Bijl-Hofland

Dept of General Practice and Social Medicine

CEHM 229

University of Nijmegen

P.O Box 9101

6500 HB Nijmegen

the Netherlands

Fax: 31243617084

\section{Keywords: asthma}

histamine challenge

perception

Received: March 41999

Accepted after revision July 71999
Asthma patients with a poor perception of asthma symptoms seem to have an increased risk of severe attack [1-4]. This increased risk could be caused by means of a deficient perception of physical signals which influences their health care decisions and may result in delay or even failure of therapy [5]. Good perception of symptoms is also of importance in patients with mild stable asthma. Mild asthma may deteriorate when poor perceivers do not present corresponding deteriorating symptoms. Information about the ability of perceiving bronchoconstriction might be helpful in protecting poor perceivers from a severe asthmatic attack. The treatment plan of such a poor perceiving patient may consist of training peak flow selfmonitoring and more intense supervision by the physician [6].

It has been suggested that the assessment of symptom perception associated with bronchoconstriction is a useful additional parameter to measure during provocation tests [7]. With this method the patient's perception of bronchoconstriction can be measured during a routine diagnostic test of bronchial responsiveness, and poor perceivers may be identified. Several indices are used to describe the perception of bronchoconstriction during bronchial provocation in the literature [3,7-14], indicating different aspects of perception. Some studies have used the linear regre- ssion analysis to describe the relationship between change in stimulus (bronchoconstriction) and the corresponding sensation (breathlessness), in which the slope of the regression line is used as the parameter to quantify the "sensitivity" of patients towards changes in lung function $[3,11,13-16]$. The steeper the slope the more sensitive a person is to signals of breathlessness. Another index of perception that has been used is the intensity of breathlessness at a $20 \%$ reduction in lung function from baseline; it indicates the patient's absolute perceptual magnitude $[7,8,10,12,14]$.

It is of interest to detect factors that are related to the different aspects of perception as these factors might be possible determinants of poor perception. Previously, it has been shown that the severity of bronchial responsiveness is associated with a reduced perception of airway obstruction, using the "sensitivity" index (slope) $[3,9,11,16]$. However, TURCOTTE et al. [10] found no relationship between bronchial responsiveness to histamine and the perception of bronchoconstriction using the breathlessness score at a $20 \%$ reduction in lung function as an index for the perception of bronchoconstriction. It seems that different aspects of perception (sensitivity towards changes in lung function and the absolute perceptual magnitude) are not necessarily related to the same clinical characteristics. 
Therefore, the aim of this study was to analyse two different aspects of the perception of bronchoconstriction ("sensitivity" and "absolute perceptual magnitude") in a population with mild stable asthma and to identify which clinical characteristics are related to these two aspects of perception of bronchoconstriction.

\section{Methods}

\section{Patient selection}

The perception of bronchoconstriction was measured in 128 stable asthmatic patients during an induced histamine challenge test. Patients were recruited from a research project on symptom perception in allergic asthmatic patients aged 16-60 [17]. Inclusion criteria were lower respiratory tract symptoms (wheeze, cough, phlegm production, shortness of breath), forced expiratory volume in one second $(\mathrm{FEV} 1) \geq 50 \%$ of predicted value, provocative dose of histamine causing a $20 \%$ fall in FEV 1 (PC20) $\leq 8$ $\mathrm{mg} \cdot \mathrm{mL}^{-1}$ and/or reversibility in FEV1 of at least $15 \%$ after inhalation of $800 \mu \mathrm{g}$ salbutamol (compared with baseline FEV1), no use of oral or inhaled corticosteroids. The present study was performed at the first assessment of lung function parameters after inclusion. Only asthma patients with a baseline FEV1 $\geq 50 \%$ of the predicted value qualified for a histamine challenge test with a minimum reduction in FEV1 of $\geq 20 \%$ of baseline value with at least two doubling doses of histamine to determine a patient's "perceptiveness" during this test. The study protocol was approved by the Medical Ethical Committee of the Medical Centre Dekkerswald, University of Nijmegen, the Netherlands. Informed consent was obtained from each patient.

\section{Histamine challenge}

Each patient underwent a histamine challenge test according to European Respiratory Society (ERS)-standards (tidal breathing method) [18]. Prior to testing, no short acting bronchodilators were used for at least $8 \mathrm{~h}$ and no long acting bronchodilators for at least $12 \mathrm{~h}$. Doubling concentrations of histamine starting with $0.03 \mathrm{mg} \cdot \mathrm{mL}^{-1}$ up to $16 \mathrm{mg} \cdot \mathrm{mL}^{-1}$ were administered until FEV1 had fallen by at least $20 \%$ compared with the baseline value or until a maximum of $16 \mathrm{mg} \cdot \mathrm{mL}^{-1}$ histamine was given. The bronchial response to each dose of histamine was expressed as the reduction in FEV1 as percentage of the baseline value. The PC20 was obtained from the log-dose response curve by linear interpolation.

\section{Assessment of breathlessness}

Breathlessness was measured before each measurement of FEV1 using a visual analogue scale (VAS). The subjects rated their breathlessness on a $100 \mathrm{~mm}$ horizontal VAS with the words "minimum" and "maximum" on the left and right ends. Subjects were instructed that the word minimum meant "no complaints of respiratory sensation such as shortness of breath, breathlessness or chest tightness" (all usually used indicators of respiratory sensation in the Dutch language) and maximum stood for "the worst res- piratory complaints imaginable". The subjects were instructed to place a vertical mark on the line, such that its position relative to the two extremes indicated the magnitude of respiratory sensation at the moment of the measurement. VAS values at any dose of histamine were expressed as absolute differences (in millimetres) compared with the baseline value [19].

Eight-week period of recorded peak flow and symptoms during daily life

The assessment of peak flow and symptoms in daily life was performed over 8 weeks prior to the histamine challenge test. Subjects were instructed and trained to record their degree of symptoms experienced in daily life each evening in a diary. The subjects were asked to score their symptoms (breathlessness, cough, wheeze, phlegm production, disturbed sleep because of these symptoms) experienced over the last $24 \mathrm{~h}$. This assessment of symptoms was made with a modified Borg score. All symptoms and the total amount of symptoms were expressed as the mean Borg score for the total number of days. Each morning and evening patients performed three measurements of their peak expiratory flow (PEF) with a Pocket peak flow meter (Micro Medical, Rochester, Kent, UK). Three PEF values were recorded and the highest value was retained. Variations in peak flow were determined by the following two parameters: mean peak flow variability ((highest-lowest $\mathrm{PEF}$ value)/mean PEF) and number of days (as percentage of total number of days) with a peak flow variability $>15 \%$.

\section{Analysis}

The perception of bronchoconstriction during the histamine challenge test was analysed by calculating the linear regression coefficient (slope $\alpha$ ) between the changes in VAS values and the reduction in FEV1 as percentage of the baseline value $[11,13,15]$. Furthermore, VAS values (perception score (PS)) corresponding to a reduction in FEV1 of $20 \%$ were determined by interpolation (PS20). The relationship between the perception of bronchoconstriction, measured by the two indices (slope $\alpha$ and PS20), with asthma symptoms, peak flow parameters, PC20, FEV1 (\% pred), age and sex were analysed by the Spearman correlation coefficient. Data are expressed as median (25$75 \%$ percentile).

\section{Results}

\section{Patients}

The clinical characteristics of the 128 asthmatic patients analysed are presented in table 1 . Of the 162 subjects in the original project, five had a baseline FEV $1<50 \%$ of the predicted value at the test day, one did not speak Dutch, in four patients no data of respiratory sensation were recorded, nine had a provocation test which consisted of only one doubling dose of histamine, nine subjects had a bronchial provocation test with a reduction in FEV1 of $<20 \%$ of baseline value and in six patients no data of peak flow and symptoms were recorded during the 8 week period prior to the histamine challenge test. 
Table 1. - Clinical characteristics of the study population

\begin{tabular}{lc}
\hline & Subjects $\mathrm{n}=128$ \\
\hline Age yrs & $34 \pm 11$ \\
Sex F/M & $60 / 68$ \\
PC20 mg.mL ${ }^{-1 \#}$ & $1.14(0.90-1.45)$ \\
FEV1 mL & $3192 \pm 716$ \\
FEV1 \% pred & $85 \pm 15$ \\
PEFR,morning L·s ${ }^{-1}$ & $530 \pm 128$ \\
PEFR,evening L·s ${ }^{-1}$ & $544 \pm 125$ \\
PEFR variability highest-lowestlmean* & $6.0(3.6-8.6)$ \\
PEFR variability >15\% \% of total days* & $4.5(0.0-13.0)$ \\
Total symptom score* & $0.7(0.2-1.6)$ \\
Smoking history: & \\
Current smokers \% & $24 \pm 19$ \\
Exsmokers \% & $26 \pm 20$ \\
Never smokers \% & $78 \pm 61$ \\
\hline
\end{tabular}

Data are presented as mean \pm SD unless indicated otherwise. ${ }^{\#}$ : geometric mean with $95 \%$ confidence interval in parenthesis; *: median with $25-75$ percentile in parentheses. F: female; M: male; $\mathrm{PC} 20$ : provocative dose of histamine causing a $20 \%$ fall in forced expiratory volume in one second (FEV1); PEFR,morning: peak expiratory flow rate, morning value; PEFR,evening: peak expiratory flow rate, evening value.

\section{Perception of bronchoconstriction}

The median value of the breathlessness score at the heart of the histamine challenge test was $8 \mathrm{~mm}$ VAS (25-75 percentile: $2-18 \mathrm{~mm}$ ). The median value of the reduction in FEV1 as percentage of baseline value was 26\% (25-75 percentile: $23-31 \%$ ) and the median value of the maximum change in VAS value during bronchial provocation was 28 $\mathrm{mm}$ (25-75 percentile: $17-40 \mathrm{~mm}$ ). The index for the sensitivity towards changes in lung function, quantified by the linear regression coefficient of change " $(\Delta) \mathrm{VAS} / \mathrm{FEV} 1 "$ (slope $\alpha$ ) was 0.91 (25-75 percentile: $0.48-1.45$ ) (fig. 1). Examples of four different perceivers based on the slope are presented in figure 2 . One subject did not experience breathlessness at all during the bronchial challenge (slope $=0$ ). In two subjects the breathlessness decreased while their FEV1 had been reduced (slope $<0)$. The med-

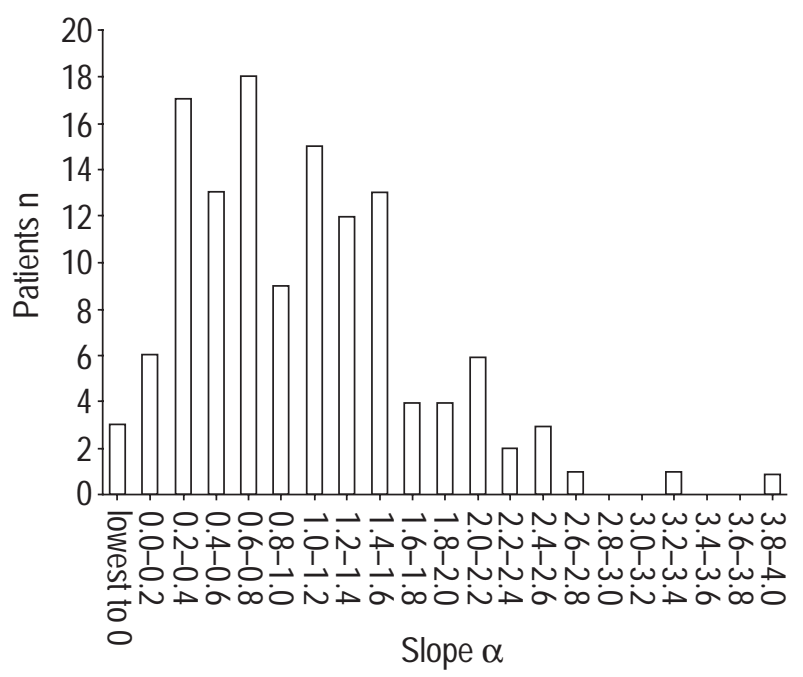

Fig. 1. - Histogram of the values of linear regression slopes $\alpha$ as an index of the patient's "sensitivity" towards changes in forced expiratory volume in one second during the histamine challenge test. The slope $\alpha$ median (25-75 percentile) value was $0.91(0.48-1.45)$.

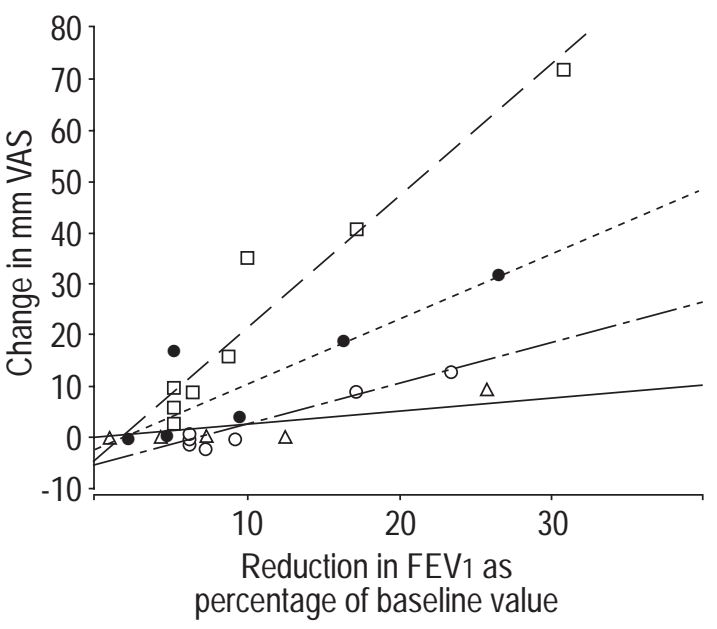

Fig. 2. - Perception of bronchoconstriction (slope $\alpha$ ) during histamine challenge by four different perceivers. The slope a represents the relationship between the changes in visual analogue scale (VAS) value and the reduction in forced expiratory volume in one second (FEV1) as percentage of baseline value. $\square$ : patient 14 , slope $=2.55$; $\bullet$ : patient 12 , slope $=1.26 ; \bigcirc$ : patient 10 , slope $=0.70 ; \triangle$ : patient 8 , slope 0.26 .

ian value of the VAS value at a $20 \%$ fall in FEV1 (PS20), as index of the absolute perceptual magnitude, was 35 mm (25-75 percentile: $19-51 \mathrm{~mm}$ ) (fig. 3). The Spearman rank correlation between slope $\alpha$ and PS20, was 0.60 (p-value=0.001) (fig. 4).

Effect of peak flow, symptoms, airway responsiveness and airway calibre

Table 2 shows that there were significant relationships between the perception of bronchoconstriction (slope $\alpha$ ) and evening peak flow $\left(\mathrm{R}_{\mathrm{s}}=0.18 ; \mathrm{p}<0.05\right)$, with the percentage of days with a peak flow variability $>15 \%$ (Rs= $-0.21 ; \mathrm{p}<0.05)$ as well as with bronchial responsiveness $\left(\mathrm{R}_{\mathrm{s}}=0.37 ; \mathrm{p}<0.001\right)$ and $\mathrm{FEV} 1$ as percentage of predicted $\left(\mathrm{Rs}_{\mathrm{s}}=0.22 ; \mathrm{p}<0.05\right)$ but not with symptoms during daily life. On the other hand, patient's (PS20) did correlate

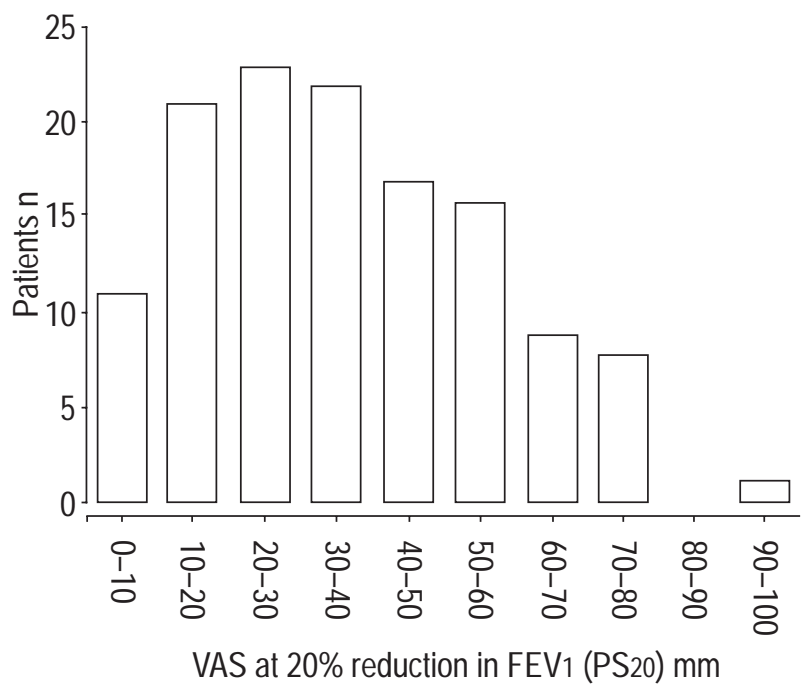

Fig. 3. - Histogram of the values of visual analogue scale (VAS) values corresponding to a reduction in forced expiratory volume in one second (FEV1) of $20 \%$ determined by interpolation (PS20) as index of the patient's "absolute perceptual magnitude" of the intensity of breathlessness. 


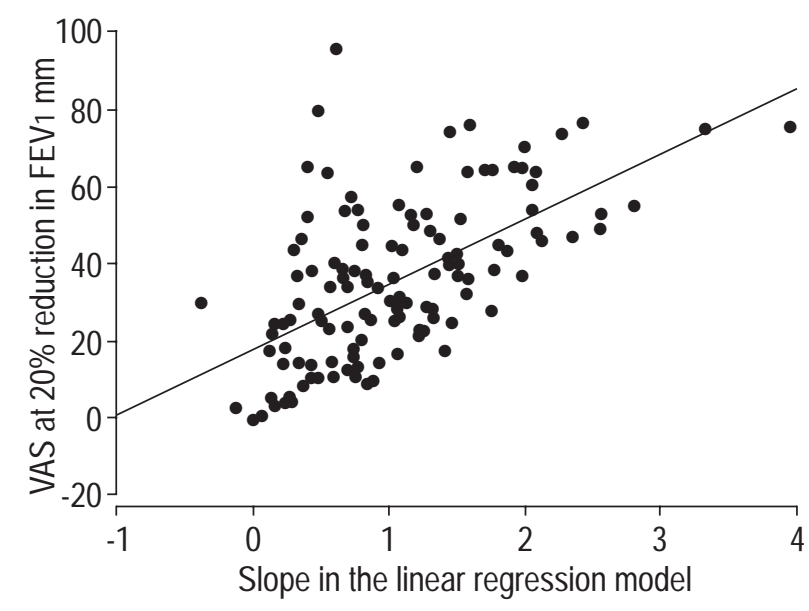

Fig. 4. - Scatterplot of the relationship between the "sensitivity" index (slope $\alpha$ in the linear regression model, $\Delta \mathrm{VAS}=\mathrm{k}+\alpha(\% \mathrm{FEV} 1$, where $\triangle$ VAS: change in visual analogue scale; $\mathrm{k}$ : a constant; FEV1: forced expiratory volume in one second), with the "absolute perceptual magnitude" index (perception score at $20 \%$ reduction in FEV1; PS20) Rs $=0.60$; $\mathrm{p}$-value $=0.001$.

significantly with symptoms during daily life (significant correlations varies from 0.21 to 0.32 ; all $\mathrm{p}<0.05$ ) but not with the lung function parameters (table 2). PS20 showed a slight but significant correlation with bronchial responsiveness $\left(R_{s}=0.19 ; \mathrm{p}<0.05\right)$.

\section{Discussion}

In this study it was found that the severity of asthma, reflected by a low lung function and a high bronchial responsiveness was associated with a low "sensitivity" towards changes in lung function. This result agrees with the study of BURDON et al. [11], a pioneer study in which an inverse relationship between the severity of asthma and perception of bronchoconstriction was demonstrated in 45 subjects. However, the key issue in this relationship is the question, what is the cause and what is the consequence? It is possible that subjects with a poor perception did not seek sufficient treatment in the past, which might have resulted in a more severe degree of asthma. Alternatively, it might also indicate that subjects with a more severe chronic asthma have become adapted to changes in lung function which might have resulted in a reduced awareness of changes in bronchoconstriction. Such an adaptive mechanism has been suggested by BuRKI et al. [20]. There was no relationship between lung function and the perceptual magnitude at a $20 \%$ reduction in FEV1.

On the other hand, patients with more symptoms had a higher breathlessness score at a $20 \%$ fall in FEV1, while there was no relationship between symptoms during daily life and the "sensitivity" towards changes in lung function. The relationship between symptoms during daily life and the perceptual magnitude at a $20 \%$ reduction in FEV 1 is not unexpected: patients with a higher absolute degree of perceived breathlessness during histamine challenge will probably assess other asthma symptoms during daily life (such as wheeze, cough, phlegm production) with relatively the same perceptual magnitude.

Poor perceivers without presentation of symptoms during daily life in combination with a relatively more severe degree of asthma may be most at risk because they are more likely to fail to seek sufficient treatment when their asthma deteriorates. When $25 \%$ of the subjects with the poorest perception were selected (based on the "sensitivity" towards changes in lung function), over one third of these subjects had very little symptoms in combination with a more severe degree of asthma. These patients should receive more intense supervision from the physician and their treatment plan may consist of training for peak flow automonitoring [6]. The use of a peak flow meter might influence the subjective assessment of asthma and may improve the perception of bronchoconstriction. The self assessment of asthma has been shown to be influenced by the knowledge of recent PEF measurement [21]. In the

Table 2. - Relationship between the indices of perception of bronchocostriction ("senstivity" index slope $\alpha$ and "absolute perceptual magnitude" index PS20) and clinical characteristics

\begin{tabular}{|c|c|c|c|c|}
\hline & \multicolumn{4}{|c|}{ Perception index } \\
\hline & \multicolumn{2}{|c|}{ slope $\alpha$} & \multicolumn{2}{|c|}{ PS20 } \\
\hline & Rs & p-value & Rs & p-value \\
\hline Age yrs & 0.06 & 0.482 & -0.12 & 0.193 \\
\hline Sex male $=0 ;$ female $=1$ & -0.12 & 0.170 & -0.09 & 0.337 \\
\hline PEFR variability highest-lowestlmean* & -0.16 & 0.071 & 0.04 & 0.625 \\
\hline PEFR variability $>15 \% \%$ of total days $*$ & -0.21 & 0.018 & 0.01 & 0.950 \\
\hline PEFR,morning $L \cdot \mathrm{s}^{-1}$ & 0.17 & 0.051 & 0.04 & 0.644 \\
\hline PEFR,evening $\mathrm{L} \cdot \mathrm{s}^{-1}$ & 0.18 & 0.047 & 0.05 & 0.568 \\
\hline $\mathrm{PC} 20 \mathrm{mg} \cdot \mathrm{mL}^{-1 \#}$ & 0.37 & 0.000 & 0.19 & 0.036 \\
\hline FEV1 \% pred & 0.22 & 0.014 & -0.04 & 0.344 \\
\hline \multicolumn{5}{|l|}{ Symptoms } \\
\hline Breathlessness & 0.00 & 0.970 & 0.32 & 0.000 \\
\hline Wheeze & -0.04 & 0.618 & 0.21 & 0.020 \\
\hline Cough & 0.00 & 0.996 & 0.26 & 0.004 \\
\hline Phlegm production & 0.05 & 0.589 & 0.31 & 0.000 \\
\hline Disturbed sleep because of preceding symptoms & 0.11 & 0.208 & 0.27 & 0.002 \\
\hline Total symptom score & 0.00 & 0.990 & 0.31 & 0.000 \\
\hline
\end{tabular}

Rs: Spearman rank correlation; PEFR: peak expiratory flow rate; PEFR,morning: peak expiratory flow rate, morning value; PEFR,evening: peak expiratory flow rate, evening value; PC20: provocative dose of histamine causing a $20 \%$ fall in forced expiratory volume in one second (FEV1). 
present study there were subjects in whom the breathlessness unexpectedly decreased while their FEV1 had been reduced and there was one who did not experience breathlessness at all during the reduction in FEV1. These subjects are also patients who need special attention when their asthma deteriorates.

In the present study both aspects of the perception of bronchoconstriction, the "sensitivity" index and the "absolute degree of perceived bronchoconstriction" were correlated with each other. This relationship can be explained, to a certain extent, by the fact that the linear regression coefficient (slope $\alpha$ ) always depends on the intercept and endpoint of the regression line [22]. The VAS score at $20 \%$ reduction in FEV1 corresponds with the endpoint of the regression line. This means that a patient with a low perception score at $20 \%$ reduction in FEV1 can never show a high "sensitivity" towards changes in FEV1. However, a patient that has a high absolute degree of perceived bronchoconstriction at the $20 \%$ fall in FEV1 can both have a high or a low "sensitivity" towards changes in lung function. Despite this colinearity between the two indices, both indices show relationships with different clinical characteristics. These separate associations confirm the concept that the PS20 as index for the "absolute degree of perceived bronchoconstriction" is reflecting patients subjective judgement about the magnitude of the intensity of a sensation, while the slope $\alpha$ more represents the ability of the patients to perceive the changes in lung function [14]. Although both indices for the "perceptiveness" of patients are correlated, they obviously measure different aspects of perception and give additional information about the perception of bronchoconstriction of a patient. The "sensitivity" index describes the relation (i.e. the slope) between the change in perceptual magnitude and the change in stimulus. However, this index requires a pivot point to express the magnitude. On the other hand, the "absolute perceptual magnitude" does not include the "sensitivity" towards changes in stimuli. There may be patients with a low absolute perceptual magnitude that still have a sensitivity to the changes in lung function. These patients perceive the changes in stimulus but estimate the respiratory distress as less than patients with a high absolute perceptual magnitude. It could be conceived that irritant receptors, which are rapidly adapting to stimuli, may play a dominant role in the respiratory perceptions of these patients. Otherwise, it is possible that there are patients with a low sensitivity and a high absolute perceptual magnitude. These patients estimate their respiratory distress as very inconvenient but can hardly differentiate between different degrees of respiratory distress. This would be compatible with slowly adapting receptor properties. To the authors' knowledge, there is no experimental evidence in this field. Therefore, both indices give additional information and need to be measured to give a complete description of the symptom perception of a patient. On the basis of the present results it could be speculated that the "absolute perceptual magnitude" index might be a representation of the personally assessed inconvenience of asthma symptoms in general as well as the asthma symptoms in daily life. MAHLER et al. [23] described this in terms of the Basal Dyspnoea Index. While the "sensitivity" index reflects the ability to perceive changes in dyspnoea which might be more affected by the condition of the changes in lung function and less by the individual personality. In the qualifications of MAHLER et al. [23], this is expressed in the Transitional Dyspnoea Index. This would indicate that in the case of clinical studies in which the influence of changes in lung function on the perception of bronchoconstriction is to be evaluated, the "sensitivity" index would be a more adequate parameter when compared with the absolute perceptual parameter. In terms of clinical management of asthma, a high sensitivity index might allow the patient to make early detections of deterioration of lung function and to seek medical help at this early stage. The estimated value of a person's "sensitivity" towards changes in lung function would, however, give no information about the personally perceived inconvenience of asthma symptoms in daily life. When this is the primary aim of a clinical study the absolute perceptual magnitude should be assessed.

In general, the observed relationship between perception and clinical characteristics was weak. This means that, although lung function and airway responsiveness seem to be predictors of the "sensitivity" index, they cannot explain the variation in the perception of bronchoconstriction completely. The same can be concluded for the symptoms during daily life. Although these symptoms seem to be a determinant of the absolute breathlessness score during histamine challenge, they do not fully explain the "absolute perceptual magnitude" of a patient.

Based on the peak flow variability the degree of asthma of the patients in this study was mild. It is possible that the relationship between PEF variability and perception of bronchoconstriction would be stronger in more severe asthma patients. Furthermore, only a limited period ( 8 weeks) of peak flow and asthma symptoms were recorded in daily life, which may have also influenced the correlations between perception and clinical characteristics.

The perception of bronchoconstriction during a histamine challenge test was determined. This test has its limitations as it does not reflect the real life situation of episodes of spontaneous bronchoconstriction. Patients will probably be more focused on their respiratory sensation during a provocation test in a laboratory setting than in daily life. Furthermore, the safe surrounding of a laboratory setting might affect the patients' perception of symptoms. Finally, the relatively rapid airway narrowing during induced bronchoconstriction probably makes it more easy to assess a degree of bronchoconstriction [24].

The FEV1 as marker of the airway resistance may underestimate the degree of bronchoconstriction as the FEV1 is influenced by changes in large airways collapsibility and, for example, a deep inhalation (required for a good measurement of the FEV1) is sufficient to reduce bronchoconstriction. NosEda et al. [25] have suggested that inspiratory indices, as they are free from any collapse artefact, may better reflect bronchoconstriction. They found a strong relationship between the sensation of dyspnoea and the change in specific inspiratory resistance in a asthmatic patients [25]. However, they also have found a clear significant relationship between the sensation of dyspnoea and the FEV1 [25]. The same results were found in a study of LougheED et al. [26], in which breathlessness during induced bronchoconstriction was more strongly related with inspiratory capacity than with FEV1. Because in both studies there also was a positive correlation between breathlessness and FEV1 it was assumed 
that the FEV1 might serve, to a certain extent, as an appropriate indicator of the degree of airway obstruction whilst measuring the relationship between changes in respiratory sensation and the corresponding changes in airway obstruction.

The similarity of respiratory sensation induced by histamine challenge and spontaneous sensations of asthma is not yet established [27, 28]. PeIFFer et al. [27] showed that the perception of spontaneous airway obstruction seems to be unrelated to the severity or duration of asthma. BOUDREAU et al. [28] found no relationship between the ability to sense breathlessness during induced and spontaneous bronchoconstriction. However, the present population were mild asthmatics and experienced less variability in airway obstruction in daily life and therefore the authors were not able to measure the perception of spontaneous bronchoconstriction.

In conclusion, patients with a more severe degree of asthma in terms of lung function, peak flow variability, and bronchial responsiveness were likely to have a low "sensitivity" for changes in bronchoconstriction. Patient's "absolute perceptual magnitude" corresponded with asthma symptoms during daily life. As a considerable portion of poor perceivers had a low lung function in combination with very little symptoms, it is advisable to identify these poor perceivers by means of a histamine challenge test.

\section{References}

1. Barnes PJ. Blunted perception and death from asthma. $N$ Engl J Med 1994; 330: 1383-1384.

2. Kikuchi Y, Okabe S, Tamura G, et al. Chemosensitivity and perception of dyspnoea in patients with a history of near-fatal asthma. N Engl J Med 1994; 330: 1329-1334.

3. in't Veen JCCM, Smits HH, Ravensberg AJJ, Hiemstra PS, Sterk PJ, Bel EH. Impaired perception of dyspnoea in patients with severe asthma. Relation to sputum eosinophils. Am J Respir Crit Care Med 1998; 158: 1134-1141.

4. Ruffin RE, Latimer KM, Schembri DA. Longitudinal study of near fatal asthma. Chest 1991; 99: 77-83.

5. Redelmeier DA, Rozin P, Kahneman D. Understanding patients' decisions. Cognitive and emotional perspectives. JAMA 1993; 270: 72-76.

6. Fishwick D, Beasley R. Use of peak flow-based selfmanagement plans by adult asthmatic patients. Eur Respir $J$ 1996; 9: 861-865.

7. Boulet L, Leblanc P, Turcotte H. Perception scoring of induced bronchoconstriction as an index of awareness of asthma symptoms. Chest 1994; 105: 1430-1433.

8. Boulet LP, Cournoyer I, Deschesnes F, Leblanc P, Nouwen A. Perception of airflow obstruction and associated breathlessness in normal and asthmatic subjects: correlation with anxiety and bronchodilator needs. Thorax 1994; 49: 965-970.

9. Brand PLP, Rijcken B, Schouten JP, Koëter GH, Weiss ST, Postma DS. Perception of airway obstruction in a random population sample. Relationship to airway hyperresponsiveness in the absence of respiratory symptoms. Am Rev Respir Dis 1992; 146: 396-401.

10. Turcotte H, Corbeil F, Boulet LP. Perception of breathlessness during bronchoconstriction induced by antigen, exercise, and histamine challenges. Thorax 1990; 45: 914-918.

11. Burdon JGW, Juniper EF, Killian KJ, Hargreave FE, Campbell EJM. The perception of breathlessness in asthma. Am Rev Respir Dis 1982; 126: 825-828.
12. Boulet L, Turcotte H, Cartier A, et al. Influence of beclomethasone and salmeterol on the perception of methacholine-induced bronchoconstriction. Chest 1998; 114: 373-379.

13. Marks GB, Yates DH, Sist M, et al. Respiratory sensation during bronchial challenge testing with methacholine, sodium metabisulphite, and adenosine monophosphate. Thorax 1996; 51: 793-798.

14. Bijl-Hofland ID, Cloosterman SGM, Folgering HTM, Akkermans RP, Hoogen HJMv, Schayck CPv. Measuring breathlessness during histamine challenge: a simple standardised procedure in asthmatic patients. Eur Respir $J$ 1999; 13: 955-960.

15. Roisman GL, Peiffer C, Lacronique JG, Le Cae A, Dusser DJ. Perception of bronchial obstruction in asthmatic patients. Relationship with bronchial eosinophilic inflammation and epithelial damage and effect of corticosteroid treatment. J Clin Invest 1995; 96: 12-21.

16. Bijl-Hofland ID, Cloosterman SGM, Folgering HTM, Akkermans RP, Schayck CPv. Relation of the perception of airway obstruction to the severity of asthma. Thorax 1999; 51: 15-19.

17. Schayck CPv, Cloosterman SGM, Hofland ID, Herwaarden CLAv, Weel Cv. How detrimental is chronic use of bronchodilators in asthma and chronic obstructive pulmonary disease? Am J Respir Crit Care Med 1995; 151: 1317-1319.

18. Sterk PJ, Fabbri LM, Quanjer PH, et al. airway responsiveness: standardized challenge testing with pharmacological, physical and sensitizing stimuli in adults. Eur Respir J 1993; 6: 53-83.

19. Peiffer C, Toumi M, Razzouk H, Marsac J, Lockhart A. Relationship between spontaneous dyspnoea and lability of airway obstruction in asthma. Clin Sci 1992; 82: 717724.

20. Burki NK, Mitchell K, Chaudhary BA, Zechman FW. The ability of asthmatics to detect added resistive loads. $\mathrm{Am}$ Rev Respir Dis 1978; 117: 71-75.

21. Higgs CMB, Richardson RB, Lea DA, Lewis GTR, Laszlo G. Influence of knowledge of peak flow on self assessment of asthma: studies with a coded peak flow meter. Thorax 1986; 41: 671-675.

22. Harver A, Tenney SM, Baird JC. A cautionary note on the interpretation of the power law for respiratory effort. $\mathrm{Am}$ Rev Respir Dis 1986; 133: 341-342.

23. Mahler DA, Weinberg DH, Wells CK, Feinstein AR. The measurement of dyspnoea. Contents, interobserver agreement, and physiologic correlates of two new clinical indexes. Chest 1984; 85: 751-758.

24. Turcotte H, Boulet L. Perception of breathlessness during early and late asthmatic responses. Am Rev Respir Dis 1993; 148: 514-518.

25. Noseda A, Schmerber J, Prigogine T, de Maertelaer V, Yernault JC. Perception of dyspnoea during acute changes in lung function in patients with either asthma of COPD. Respir Med 1995; 89: 477-485.

26. Lougheed MD, Lam M, Forkert L, Webb KA, O'Donnell DE. Breathlessness during acute bronchoconstriction in asthma. Am Rev Respir Dis 1993; 148: 1452-1459.

27. Peiffer C, Marsac J, Lockhart A. Chronological study of the relationship between dyspnoea and airway obstruction in symptomatic asthmatic subjects. Clin Sci 1989; 77: 237-244.

28. Boudreau D, Styhler A, Gray-Donald K, Martin JG. A comparison of breathlessness during spontaneous asthma and histamine-induced bronchoconstriction. Clin Invest Med 1995; 18: 25-32. 